\title{
REVISIÓN COMPARADA DE LOS DERECHOS COMUNALES EN LA LEGISLACIÓN DE TENENCIA DE TIERRA Y BOSQUES EN PERÚ, INDONESIA, MOZAMBIQUE Y UGANDA ${ }^{(1)}$
}

\author{
PERU SUYUPI, INDONESIA SUYUPI, MOZAMBIQUE SUYUPI, \\ UGANDA SUYUPIWAN SACHASACHAKUNAQ HINASPA \\ ALLPAKUNAQ HAP'ISQANKU AMACHAYNIN UKHUPI \\ KAMACHIY
}

\section{COMPARATIVE REVIEW OF COMMUNAL RIGHTS IN LAND AND FOREST TENURE LEGISLATION IN PERU, INDONESIA, MOZAMBIQUE AND UGANDA}

\section{Carlos Antonio Martin Soria Dall'Orso(2)}

Ch'uyanchakuy: Kay articuloqa qawarimun Peru suyupi, Indonesia suyupi, Uganda Suyupi, Mozambique suyupiwan imaynas chay derecho comunitario nisqa, imapis kuskalla purichayku tarinapaq. Chaypaqmi chay suyukunaq khuskiykunanpi qimikuni. Legislaciunta khuskini imaymana qawakuykuna ruwaykunawan kallpachasqa derechukunata ayllukunapi kasqanmanta. Kay Tenencia nisqa wacharimun derecho consuetudinario nisqamanta y ayllukunaq yachaykunamanta, chaymanta huñunakunku chay derecho positivo sistema legal nisqatawan. Kunankaman kawsan chay sistema colonial nisqanku derechopi. Kay yachayqa imaymanata pachamamanchismanta orquyllata munan, manan munanchu imaymana ayllukunapi kawsaykunata. Kay Khuskiyqa chay tawa suyukunapi ruwaykunata qawarin, qayakunaman khuskinapaq.

(1) Agradezco a CIFOR, en las personas de Anne Larson e lliana Monterroso, a la Comisión Europea, el Fondo para el Medio Ambiente Mundial (GEF), el Fondo Internacional de Desarrollo Agrícola (FIDA) y la Organización de las Naciones Unidas para la Alimentación y la Agricultura (FAO) por su apoyo para desarrollar los estudios Soria (2016 a y b y 2017 a). Dichos estudios aportan importantes elementos para elaborar esta ponencia para el Congreso Internacional sobre Avances en la Seguridad de Tenencia: La Tierra y el Bosque, a desarrollarse en el Auditorio Auxiliar de la Universidad Nacional Agraria La Molina (UNALM), en Lima, del 12 al 14 de junio de 2018.

(2) Abogado por la Pontificia Universidad Católica del Perú PUCP; Maestro en Ciencias Sociales con mención en Estudios Amazónicos por la Facultad Latinoamericana de Ciencias Sociales FLACSO Sede Ecuador y Ph. D. por La Universidad Flinders de Australia del Sur. 
Yuyaysapa simikuna: Allpa, Runakuna, Qelqa kamachi, Ayllu kaqniyoq, Sach'a sach'akuna

Resumen: Este artículo identifica los niveles de consistencia o robustez de la legislación sobre tenencia comunitaria en Perú, Indonesia, Uganda y Mozambique a fin de formular elementos comunes y singulares que la afectan. Para ello me apoyo en estudios realizados para cada país en base a una matriz de principios, valores e indicadores desarrollada al efecto. Se analiza la legislación con una mirada interdisciplinar para valorar la robustez de los derechos de tenencia comunal. Esta tenencia que nace del derecho consuetudinario y el conocimiento tradicional luego se nutre de sus interacciones con el sistema de derecho positivo y legalista. El sistema legal positivo es resultado del proceso colonial y postcolonial y de su ideología y escala de valoración de la realidad, los mismos que aún perduras en la legislación, así como en elementos de la población. Esta ideología es fuertemente privatizadora, justifica la expoliación del otro, el saqueo de recursos naturales y niega la importancia de modelos que atiendan a la diversidad de formas de propiedad que existen en la realidad. Cuando una legislación así se sensibiliza frente a la tenencia comunal entonces propone una formula discursiva sin recursos para su implementación ni herramientas para el monitoreo, reporte, verificación y sanción de sus resultados. Este análisis revisa esas experiencias en estos cuatro países a fin de identificar una futura agenda de investigación.

Palabras clave: Tierra, Pueblos indígenas, Legislación, Propiedad Comunal, Bosques.

Abstract: This paper identifies the levels of consistency or robustness of community tenure legislation in Peru, Indonesia, Uganda and Mozambique in order to formulate common and singular elements that affect it. I use studies carried out for each country based on a matrix of principles, values and indicators developed for this purpose. The legislation is analysed with an interdisciplinary perspective to assess the robustness of communal tenure rights. Communal tenure is based on customary law and traditional knowledge and also nourished by their interactions with the legal and positive legal system. The positive legal system is the result of the colonial and postcolonial processes. Its ideology and values still exist in the legislation as well as in elements of the population. This ideology is strongly in favour of privatizing, justifies the spoliation of the other, the plundering of natural resources and denies the importance of models that address the diversity of forms of property that exist in reality. When such legislation is sensitized to communal tenure then it proposes a legal discursive formula with no resources for its implementation or tools for monitoring, reporting, verification and sanctioning. This analysis reviews these experiences in these four countries in order to identify a future research agenda.

Key words: Lands, Indigenous peoples, Law, Communal ownership, Forests 


\section{Introducción}

La Carta de los Bosques de 1217 estableció con claridad los derechos de los comunes o usuarios de los bosques, así como su relación con los derechos de los señores de la tierra y los bosques (gobierno condal o provincial) y el rey (gobierno central) en Inglaterra. Un interesante entramado de normas legales dispone las pautas para la operación de las varias autoridades forestales, así como reglas detalladas sobre los precios que deben pagar los usuarios de las vías, las necesarias para ocupar una arboleda, para abrir una parcela en el bosque o construir una casa, así como las pertinentes a la caza siendo garantizado a todos el derecho a los animales menores y requiriéndose permiso para las piezas de caza mayor. CHOMSKY (2015) nos dice que hubiera hecho mucho bien a la democracia que esta Carta de los Bosques se difundiera tanto como su hermana la Carta Magna.

La sigilosa desaparición de esta carta del conocimiento público ha favorecido la idea de que los comunes, bosquecinos o poblaciones tradicionales de los bosques no tienen derechos o en todo caso sus usos son perjudiciales al bienestar del bosque y de la convivencia social. Adicionalmente el proceso histórico de la colonización europea sobre los otros continentes favoreció la imposición de un modelo basado en la paradoja de la inclusión/exclusión de la cual habla MERINO $(2017,121)$. $^{(3)}$ En 1957 el Convenio 107 de la OIT proponía 'integrar' a estas poblaciones a la sociedad 'mayor'. El gran cambio recién llega en 1989 con el Convenio 169 de la OIT que garantiza el derecho de propiedad y posesión a las áreas bajo (SORIA 2016 b, 22): a) propiedad; b) posesión; y c) acceso tradicional a áreas ocupadas por terceros; propone el respeto a que los indígenas escojan las prioridades de su desarrollo y pide que se consulte las propuestas de normas, políticas y proyectos que pudieran afectarlos. Sin embargo la colonialidad persiste incólume ${ }^{(4)}$ sobre todo en la mente de quienes rechazan informarse sobre la Declaración Universal de Derechos Humanos de 1948 o sobre el Convenio 169 de la OIT de 1989 y la Declaración de Naciones Unidas sobre los Derechos de los Pueblos Indígenas de 2007. Como señala BRUCE $(1992,7)$ la posesión de la tierra más que una cuestión legal o de productividad es un asunto profundamente político.

(3) 'After colonisation, the political and economic elites constructed states under European models according to which the state was the legal and political expression of a homogeneous social collective (a 'nation'). Therefore, Indigenous Peoples have to be either included within these new nation-states (denying their different social, political and economic arrangements) or excluded from them (which meant in some contexts the legal and material elimination of these peoples).'

(4) 'Coloniality denotes that, even though colonial rule has ended in formal legal and political terms, power remains distributed according to a colonial ontology and epistemology. This explains why social, legal and economic relationships regarding Indigenous Peoples still respond to an inclusion-exclusion paradox' (Merino 2017, 121). 
Los sistemas de tenencia consuetudinarios obtienen su legitimidad de la confianza que una comunidad deposita en las personas e instituciones que gobiernan el sistema. Estas personas son descendientes de los primeros comuneros, a menudo los ancianos varones suelen ser depositarios de estas normas de tenencia y las trasmiten a las siguientes generaciones. Así la tenencia consuetudinaria refleja los valores culturales y sociales de la comunidad, usualmente diferenciando entre locales y externos, desglosar múltiples usos y usuarios de los múltiples recursos del territorio desde la recolección, la caza, la pesca y otros usos no permanentes del suelo. Estas complejas, diferenciadas y flexibles reglas de tenencia a menudo protegen los intereses de sus miembros más desfavorecidos, vulnerables y minorías. En general son reglas relativamente laxas, cuando los recursos son abundantes y la demanda es baja. A medida que aumenta la demanda las reglas de acceso, intercambio y herencia se vuelven más intrincadas o restrictivas. Asimismo, las reglas pueden surgir repentinamente o rescindirse a medida que se renegocian los derechos sobre la tierra, los bosques, los barbechos y los recursos hídricos para abordar las nuevas realidades económicas y ambientales. Así la tenencia consuetudinaria es una 'institución viva'. Esta vitalidad le permite adaptarse en respuesta al crecimiento poblacional, las fuerzas del mercado, los cambios políticos, los conflictos e incluso el cambio climático (DA CUNHA 1990, STAVENHAGEN 1990, 21; FREUDENBERGER 2013, 2-3).

En la mayoría de los países de África, Asia y América Latina, varios sistemas legales, positivos y consuetudinarios e internacionales, coexisten y colaboran o se disputan el mismo espacio físico, lo que resulta en derechos superpuestos, reglas contradictorias y autoridades en competencia. Hay casos en que los sistemas legales y consuetudinarios coexisten en armonía y proporcionan un grado razonable de estabilidad de la tenencia (STAVENHAGEN 1990, 29). SANTOS (2002, 297-298) Ilama a estos complejos y variados procesos 'Interlegalidad' mientras que Cotula, Toulmin y Quan hablan de complejos mosaicos de sistemas de tenencia (2007 citado por FREUDENBERGER 2013, 5) y STAVENHAGEN $(1990,17)$ nos dice que el sistema consuetudinario no existe por si solo sino que siempre debe entenderse también en su relación con el sistema jurídico del Estado.

\subsection{Metodología}

Con estos antecedentes paso a revisar varias fuentes (FAO 2011 y 2012, DAVIS et al, 2013, DAVIS 2015, SAFITRI 2015) que aportan principios, valores e indicadores para definir una propuesta de análisis de la fortaleza de los sistemas de tenencia, en especial la tenencia comunal de la tierra y los bosques en Perú, Indonesia Mozambique y Uganda.

DAVIS (2015) integra los marcos y guías de gobernanza forestal del 
Marco Indicador de la Iniciativa de Gobernanza Forestal del Instituto de Recursos Mundiales (DAVIS et al, 2013), el Marco de la Organización para la Agricultura y la Alimentación para Evaluar y Monitorear la Gobernanza Forestal (2011) y las Directrices de la FAO sobre Responsabilidad de la tenencia de la tierra, la pesca y los bosques (2012) en once indicadores para evaluar la idoneidad de los marcos jurídicos nacionales para proteger y promover los derechos de tenencia de las comunidades forestales: 1) Alcance de los derechos garantizados; 2) Duración de los derechos; 3) Claridad y consistencia dentro y entre las leyes forestales; 4) Obligaciones impuestas a los estados; 5) Grado reconocimiento de los derechos; 6) Número y naturaleza de las restricciones; 7) Garantías legales contra la extinción unilateral de derechos; 8) Mecanismo de aplicación de derechos y resolución de disputas; 9) Naturaleza y alcance de los recursos en caso de violación de los derechos de tenencia; 10) Sensibilidad de género y no discriminación; y 11) Claridad de la autoridad y las responsabilidades institucionales. DAVIS (2015) hace el esfuerzo de explicar cada categoría de indicador sin proporcionar criterios de puntuación para evaluar la mejora de la tenencia comunal de la tierra. De DAVIS recojo para integrar al marco de evaluación de las fortalezas del régimen de tenencia de los indicadores: sensibilidad de género y no discriminación, número y naturaleza de las restricciones y garantías legales contra la extinción unilateral de derechos.

De otro lado, SAFITRI (2015) propone indicadores detallados para evaluar la legislación de tenencia de la tierra comunitaria de Indonesia. SAFITRI cubre la mayoría de las preocupaciones de NARUWAILO y luego proporciona principios y variables a considerar, así como desarrolla una tarjeta de puntuación. SAFITRI identifica tres categorías de principios globales, que son la robustez de los derechos, la protección de los derechos y la garantía de los derechos. Estos principios organizan un conjunto de indicadores y variables a considerar para cada caso. Así busca medir la robustez de los derechos a través de la legalidad, la claridad, el conjunto de derechos involucrados, la duración de los derechos y el género. Para la categoría protección del derecho considera necesario revisar la gestión de quejas, la resolución de conflictos y la compensación. Finalmente, para evaluar la categoría garantía de los derechos propone revisar la participación, el aseguramiento de la sostenibilidad forestal y la garantía de acceso a poder económico. Luego desarrolla indicadores de calificación para evaluar el cumplimiento de cada uno de estos elementos a considerar. Los puntajes van de 1 a 10 para evaluar cinco cualidades de la seguridad legal de la tenencia en cada indicador: seguridad jurídica muy fuerte (valor de 9 a 10), fuerte $(7-8,99)$, moderada $(5-6,99)$, débil $(3-4,99)$ y seguridad muy débil (1-2.99). ${ }^{(5)}$ Con este marco metodológico y conceptual propuse en SORIA (2016 b) una integración de las propuestas de FAO 2011 y 2012; DAVIS, WILLIAMS, LUPBERGER y DAVIET 2013; DAVIS 2015; y SAFITRI 2015, que se resume en el siguiente cuadro. 


\begin{tabular}{|c|c|c|}
\hline \multicolumn{3}{|c|}{ CUADRO 1 INDICADORES DEL RESPETO ALOS DERECHOS DE TENENCIA } \\
\hline Principios & Indicadores & Variables \\
\hline \multirow{5}{*}{$\begin{array}{l}\text { Robustez de } \\
\text { los Derechos }\end{array}$} & 1.1 Legalidad & $\begin{array}{c}\text { Base legal clara y estable; Reconocido y otorgado por la autoridad; } \\
\text { Clara división de autoridad y responsabilidades entre diferentes niveles } \\
\text { de gobierno en relación al otorgamiento y protección; Legislación } \\
\text { armónica entre sí y con reglamentos. }\end{array}$ \\
\hline & 1.2 Claridad & $\begin{array}{l}\text { Criterio claro del titular como sujeto de derecho; Tipo claro y límites del } \\
\text { objeto del derecho; Contenido claro de los derechos y obligaciones; } \\
\text { Procedimiento claro para obtener y defender los derechos. }\end{array}$ \\
\hline & 1.3 Conjunto de Derechos & $\begin{array}{l}\text { Derecho de acceso; Derecho de withdrawal Derecho de gestión; } \\
\text { Derecho de exclusión y Derecho de transferir }\end{array}$ \\
\hline & 1.4 Duración & Mientras más dure, más seguro el derecho. \\
\hline & 1.5 Género & $\begin{array}{l}\text { Las políticas de gestión de la tenencia proveen principios y normas } \\
\text { operacionales para desarrollar un enfoque de género }\end{array}$ \\
\hline \multirow{5}{*}{$\begin{array}{l}\text { Protección de } \\
\text { los Derechos }\end{array}$} & 2.1 Manejo de Quejas & Mecanismo de queja asequible \\
\hline & 2.2 Resolución de Conflictos & Asequible, de costo razonable y mecanismo justo \\
\hline & 2.3 Compensación & $\begin{array}{l}\text { Formas apropiadas de compensación por la pérdida de derechos; } \\
\text { Mecanismo adecuado para obtener compensación. }\end{array}$ \\
\hline & 2.4 Número y naturaleza de las restricciones & $\begin{array}{l}\text { Las políticas de gestión de la tenencia evitan imponer restricciones no } \\
\text { razonables sobre el ejercicio del derecho }\end{array}$ \\
\hline & $\begin{array}{c}\text { 2.5 Garantías legales contra la extinción unilateral } \\
\text { de derechos }\end{array}$ & $\begin{array}{l}\text { Las políticas y legislación deben otorgar garantías de que los derechos } \\
\text { de tenencia no serán retirados, cambiados unilateralmente o } \\
\text { injustamente. }\end{array}$ \\
\hline \multirow{3}{*}{$\begin{array}{l}\text { Garantía de } \\
\text { los Derechos }\end{array}$} & 3.1 Participación & Población participa de la toma de decisiones. \\
\hline & 3.2 Garantía de la Sostenibilidad Forestal & El gobierno garantiza la buena calidad del ecosistema forestal. \\
\hline & 3.3 Garantía del Empoderamiento Económico & $\begin{array}{l}\text { El gobierno a todo nivel facilita la mejora de las condiciones de vida del } \\
\text { titular de derechos. }\end{array}$ \\
\hline
\end{tabular}

Fuentes: FAO 2011 y 2012; DAVIS, WILLIAMS, LUPBERGER y DAVIET 2013; DAVIS 2015; SAFITRI 2015, y SORIA 2016 b. Elaboración propia.

\section{Situación de la legislación de tenencia comunitaria en Perú}

En SORIA (2016 a) presente un listado de la legislación relevante que afecta la tenencia comunal en Perú. Este identifica al menos 60 normas legales de varios niveles que influyen sobre las condiciones de la tenencia comunitaria de recursos naturales en la Amazonia peruana en el periodo 1978-2016. En SORIA (2016 b) caracterice de manera general esas 60 normas: 28 de ellas dan mayor o menor apoyo a la propiedad y la gestión comunal; 51 de ellas se refieren a procedimientos en apoyo de la propiedad individual de la tierra y su gestión. ${ }^{(6)}$ De las 28 normas que ayudan a implementar la tenencia comunal de la tierra, 14 de ellas son referidas a tenencia comunal de tierras y las otras 14 se refieren a: pueblos indígenas que viven en comunidades nativas (2); pueblos indígenas no contactados y de contacto inicial (7) y legislación sobre consulta previa (5) que involucra derechos de tenencia de la tierra (SORIA 2016 b, 35-42). Las principales normas que favorecen la tenencia comunal de la tierra son la Constitución de 1993, el Decreto Ley 22175/1978, el Convenio OIT 169/1989 (vigente en Perú desde febrero de 1995), la Ley 28736/2006 de Protección de los Pueblos Indígenas en Situación de Aislamiento e Inicial Contacto, la Ley 29763/2011 Ley de Silvicultura y Fauna Silvestre y el Decreto Supremo 021-2015-MINAGRI que prevé el manejo

(6) Dado que una norma legal contiene una variedad de artículos, muchas veces una ley que apoya la tenencia comunal también apoya la tenencia individual, por tanto no se pueden sumar los números parciales y esperar que den el total. 
de bosques comunales de diversos tipos (madera, forestal no maderable y fauna silvestre) y la Ley 29785/2011 Ley de Consulta Previa (SORIA 2016 b, 44).

De las 51 normas que apoyan la tenencia individual de la tierra, 23 son directamente de tenencia individual de la tierra y las otras 28 son normas referidas a la gobernanza de la tenencia de la tierra (20); mercado (3); minería (2) y (3) legislación de conservación que involucra derechos de tenencia de la tierra. Es necesario mencionar que al menos 6 leyes tienen regulaciones que implementan la tenencia comunal de la tierra, la tenencia pública de la tierra y la tenencia privada de la tierra, como la Ley de Áreas Naturales Protegidas Ley 28634/1997. Esta es la razón por la cual estas leyes aparecen en varias de las categorías, ya que contienen muchas reglas o artículos con diversos propósitos. Esto expresa una situación que también ocurre en la Constitución de 1993 donde las tres formas de propiedad tienen un estatus legal similar, algo que no sucede en la práctica diaria donde los funcionarios han solido priorizar la tenencia individual y solo en algunos periodos o en algunas instituciones se reconoce un apoyo a la tenencia comunal (SORIA 2016 b, 44). Las principales leyes que favorecen la tenencia individual de la tierra son el Decreto Legislativo 653/1991 Ley para la Promoción de la Inversión en el Sector Agrario y sus reglamentos, incluso la misma Ley 26834/1997 que favorece las reservas comunales también favorece la consolidación de áreas protegidas superpuestas sobre territorios indígenas, comunidades indígenas (fue solo después de la negociación de 2001 entre pueblos indígenas amazónicos y el Estado que se acordó no crear áreas protegidas sobre comunidades nativas) o pueblos indígenas no contactados y de contacto inicial, el Decreto Legislativo 667/1991 Ley de Registro de Predios Rurales y otras 20 piezas que regulan procesos de titulación individual de la tierra, la Ley 26505/1995 para la inversión privada en comunidades nativas, y otros.

\subsection{Hallazgos sobre tenencia comunitaria en Perú}

La legislación peruana vigente apoya en su mayoría la titulación individual de la tierra, que es de hecho la fuerza que impulsa la conversión de la cubierta forestal afectando la tenencia comunal y publica, obviamente con diferentes características en diferentes regiones de la Amazonia peruana. Sin embargo, la legislación peruana también ha sido influenciada por el enfoque de derechos humanos en apoyo de las comunidades nativas y los pueblos indígenas en aislamiento y contacto inicial. Estos enfoques ocurren en una cierta contienda entre la tenencia de la tierra individual y la tenencia comunal y pública de la tierra. Esta contienda se refleja también en los debates políticos entre las fuerzas políticas, con un aporte sustancial de movimientos sociales como las organizaciones de pueblos indígenas (SORIA 2016 b, 44).

En SORIA (2016 b) establecí que la mayoría de los indicadores de la fortaleza de los derechos sobre la tenencia de la tierra por pueblos indígenas en la 
legislación peruana tienen un puntaje Débil (3) o Muy Débil (3), mientras que casi la otra mitad se califica como Moderada (5). La duración ilimitada de los derechos de tenencia de tierras de los pueblos indígenas es el único factor fuerte de nuestra legislación colectiva sobre la tenencia de la tierra.

\begin{tabular}{|c|c|c|c|c|c|c|c|c|c|c|c|}
\hline \multicolumn{12}{|c|}{ CUADRO 2 LA TENENCIA DE TIERRAS Y BOSQUES INDIGENAS POR PUEBLOS INDIGENAS EN PERÚ } \\
\hline \multirow{2}{*}{$\begin{array}{c}\text { RELACION } \\
\text { CON EL } \\
\text { TITULAR } \\
\text { DEL AREA } \\
\end{array}$} & \multirow{2}{*}{\multicolumn{3}{|c|}{$\begin{array}{l}\text { Propiedad de pueblos indígenas sobre } \\
\text { tierras y bosques }\end{array}$}} & \multicolumn{6}{|c|}{ Pueblos indígenas en posesión de áreas protegidas o tierras y bosques del Estado } & \multirow{2}{*}{\multicolumn{2}{|c|}{$\begin{array}{c}\text { Pueblos indigenas en } \\
\text { posesión de bosques } \\
\text { privados }\end{array}$}} \\
\hline & & & & \multicolumn{3}{|c|}{ Áreas Protegidas B } & \multicolumn{3}{|c|}{ osques Estatales } & & \\
\hline $\begin{array}{c}\text { TIPO DE } \\
\text { TITULO EN } \\
\text { EL QUE SE } \\
\text { EJERCE EL } \\
\text { DERECHO }\end{array}$ & $\begin{array}{c}\text { Tierras y } \\
\text { bosques } \\
\text { bajo titulo } \\
\text { de } \\
\text { propiedad } \\
\text { comunal }\end{array}$ & $\begin{array}{c}\text { Tierra en } \\
\text { propiedad } \\
\text { bajo titulo } \\
\text { comunal }\end{array}$ & $\begin{array}{c}\text { Título de } \\
\text { propiedad } \\
\text { individual } \\
\text { de una } \\
\text { persona } \\
\text { indígena }\end{array}$ & $\begin{array}{c}\text { Pueblos } \\
\text { indígenas } \\
\text { en posesión } \\
\text { de ares } \\
\text { protegidas } \\
\text { anteriores } \\
\text { a } 1997\end{array}$ & $\begin{array}{c}\text { Área } \\
\text { Protegida } \\
\text { Reserva } \\
\text { comunal }\end{array}$ & \begin{tabular}{|c|} 
Pueblos \\
indígenas \\
no \\
contactado \\
s en \\
posesión de \\
áreas \\
protegidas \\
anteriores \\
a 1997 \\
\end{tabular} & $\begin{array}{c}\text { Tierra o } \\
\text { bosques } \\
\text { de } \\
\text { pueblos } \\
\text { indígenas } \\
\text { bajo un } \\
\text { contrato } \\
\text { de cesión } \\
\text { forestal }\end{array}$ & $\begin{array}{c}\text { Tierra o } \\
\text { bosques de } \\
\text { pueblos } \\
\text { indígenas en } \\
\text { proceso de } \\
\text { reconocimient } \\
\text { o para } \\
\text { titulación }\end{array}$ & $\begin{array}{c}\text { Tierra } 0 \\
\text { bosques de } \\
\text { pueblos } \\
\text { indígenas sin } \\
\text { iniciar proceso } \\
\text { de } \\
\text { reconocimiento } \\
\text { para titulación }\end{array}$ & $\begin{array}{c}\text { Pueblos } \\
\text { indígenas } \\
\text { no } \\
\text { contactados } \\
\text { en posesión } \\
\text { de } \\
\text { concesión } \\
\text { forestal }\end{array}$ & $\begin{array}{c}\text { Pueblos } \\
\text { indígenas } \\
\text { no } \\
\text { contactado } \\
\text { s en } \\
\text { posesión } \\
\text { de } \\
\text { concesión } \\
\text { petrolera }\end{array}$ \\
\hline $\begin{array}{l}\text { FORMA DE } \\
\text { TENENCIA }\end{array}$ & $\begin{array}{l}\text { Propiedad } \\
\text { comunal }\end{array}$ & $\begin{array}{l}\text { Propiedad } \\
\text { comunal }\end{array}$ & $\begin{array}{l}\text { Propiedad } \\
\text { individual }\end{array}$ & Posesión & $\begin{array}{l}\text { Acceso y } \\
\text { uso } \\
\text { Comunal }\end{array}$ & Posesión & Posesión & $\begin{array}{l}\text { En vía a ser } \\
\text { propiedad } \\
\text { comunal o } \\
\text { individual }\end{array}$ & $\begin{array}{c}\text { En vía a ser } \\
\text { propiedad } \\
\text { comunal } 0 \\
\text { individual }\end{array}$ & Posesión & Posesión \\
\hline
\end{tabular}

La diversidad del conjunto de derechos de tenencia de tierra de los pueblos indígenas es moderada ya que incorpora todas las formas de derechos.

La robustez de los derechos de la tenencia de la tierra de los pueblos indígenas puede calificarse como Moderada; mientras que la Protección de Derechos es Muy Débil y la Garantía de Derechos es Débil. En dicho estudio establecí que la tierra y los bosques bajo el título de propiedad comunal, la tierra bajo el título de propiedad comunal, la reserva comunal y los títulos de tierra individuales de los pueblos indígenas se clasifican como Moderados. Las 1250 comunidades nativas tituladas en el Amazonas peruano son Tierras y Bosques bajo título de propiedad comunal, Tierras bajo título de propiedad comunal, o Tierras de pueblos indígenas bajo un Contrato de Cesión de Bosques. (SORIA 2016 b, 57).

Los pueblos indígenas en posesión de tierras o bosques en proceso de reconocimiento y titulación, los pueblos indígenas en posesión de tierras o bosques sin iniciar el proceso de reconocimiento y titulación, y los pueblos indígenas no contactados en posesión de tierras en una concesión forestal se califican como formas Muy débiles de tenencia de la tierra por parte de estos pueblos indígenas (SORIA 2016 b, 56).

La posesión de pueblos indígenas sobre tierras o bosques en áreas protegidas antiguas, sobre tierras o bosques en otras áreas protegidas, sobre tierras o bosques bajo un contrato de concesión forestal y en posesión de tierras en una concesión petrolera se califica con un status Débil de tenencia de la tierra. 


\subsection{La posible evolución de los derechos de tenencia en Perú}

La legislación peruana sobre la tenencia de la tierra tiene una robustez Moderada en sus textos, pero requiere ser más sólida en la acción, la implementación, el control y la sanción de políticas. Los avances logrados por el Decreto Ley 22175/1978 y particularmente la Ley 29763/2011 y su reglamento el Decreto Supremo 021-2015-MINAGRI favorecen el acceso y manejo de tierras y bosques comunales. La mayoría de las comunidades nativas viven en una situación de derechos moderados de tenencia de la tierra. Mientras que un tercio vive en una situación de tenencia de la tierra Débil o Muy Débil (SORIA 2016 b, 57-58). Los esfuerzos actuales de los organismos internacionales y el gobierno peruano en apoyo de la tenencia de la tierra de los pueblos indígenas involucran a por lo menos once iniciativas.

Los retos institucionales a los que nos enfrentamos en el futuro son: la necesidad de un mecanismo judicial rápido para responder a las reclamaciones relacionadas con la tenencia, los delitos ambientales y otros; una voluntad clara y proactiva para cumplir las corresponsabilidades en un sistema integrado multisectorial y multinivel; la implementación efectiva de la autoridad del Estado en la supervisión y el apoyo a la gestión ambiental en las zonas rurales; y la integración de políticas de promoción de la tenencia colectiva y la conservación de la tierra con políticas para el crecimiento económico (SORIA 2015, 17; SORIA 2016 b, 58). Sin embargo, esto depende de un gobierno que comprenda la importancia de una agenda diversa y variada para las diferentes formas de tenencia de la tierra como la propiedad privada, la propiedad comunal y la propiedad pública (SORIA 2016 a, 52; SORIA 2017 a, 19).

El liderazgo político regional está muy influenciado por las fuerzas económicas regionales, que en muchos casos también son fuertes actores políticos locales. Los políticos regionales y los congresistas que dicen representar Madre de Dios, Loreto y otras regiones amazónicas son orgullosos representantes de los intereses de la madera ilegal.

A nivel de políticas, la gestión de recursos naturales basada en las comunidades tiene una legislación dispersa sobre una serie de leyes y reglamentos, una institucionalidad muy enfocada en solo hacer control y vigilancia y es necesario transitar hacia un desarrollo de políticas públicas institucionales adaptativas de aprendizaje en cogestión, con comunidades locales y otras poblaciones rurales, en tierras públicas y privadas, como parte de paisajes dinámicos y más complejos.

\section{Situación de la legislación de tenencia comunitaria en Indonesia}

La Constitución de 1945 y sus enmiendas reconocen los derechos de las personas a la tierra y los recursos naturales de tres maneras: Primero, el 
reconocimiento estatal de los derechos de las comunidades y la autorregulación de los pueblos indígenas en sus territorios, conocida como la Unidad de Comunidades Basadas en el Derecho Consuetudinario o Kesatuan Masyarakat Hukum Adat (artículo 18B, párrafo 2). Segundo, reconoce los derechos de los pueblos indígenas a la tierra como parte del reconocimiento de los derechos humanos, (artículo $28 \mathrm{I}$, párrafo 3). Tercero el derecho de los ciudadanos individuales a poseer sus bienes personales, incluida la tierra, y disfrutar de un ambiente sano (artículo $28 \mathrm{H}$, párrafos 1 y 4) (SAFITRI 2015, 20).

La protección del derecho a la tenencia es un principio de la reforma agraria y la gestión de los recursos naturales. Las principales normas que influyen sobre la tenencia comunitaria son: la Constitución de 1945 y sus enmiendas, La Ley Agraria Básica, la Ley 20/1961 de Revocación de Derechos de Tierras, la Ley 2/2012 sobre Adquisición de Tierras para el Desarrollo del Interés Público, la Ley Forestal y la Ley de Gobiernos Regionales, entre otras.

La Constitución de Indonesia enfatiza la autoridad del Estado para controlar las tierras y recursos naturales que deben utilizarse para el mayor beneficio de las personas (artículo 33, párrafo 3). El Tribunal Constitucional interpretó este mandato como la autoridad para la formulación de políticas, gobernar, regular y gestionar la tierra y los recursos naturales, supervisar la implementación de esta regulación y gestión (SAFITRI 2015, 20-22). Como tal, todos los derechos sobre la tierra privada y sobre la tierra indígena están bajo el paraguas de la autoridad del Estado para controlar la tierra y los recursos naturales. El Estado puede revocar los derechos a la tierra al otorgar una compensación a los titulares de los derechos (artículo 18 del Ley Agraria Básica). Este artículo se implementa a través de la Ley 20/1961 de Revocación de Derechos de Tierras y la Ley 2/2012 sobre Adquisición de Tierras para el Desarrollo del Interés Público. El primero es para el proceso obligatorio de abolición de los derechos a la tierra, bajo el fundamento de que todos los derechos sobre la tierra tienen funciones sociales y ecológicas; mientras que la segunda norma es para el procedimiento voluntario. Curiosamente, el Gobierno de Indonesia solo implementó una vez la Ley 20/1961 y esto fue durante la administración del presidente Soekarno. Posteriormente, el Gobierno prefirió aplicar voluntariamente el procedimiento (pembebasan tanah) que ahora está regulado por la Ley de Adquisición de Tierras (Ley 2/2012) (SAFITRI 2015).

Sobre la base del derecho del Estado al control de la tierra, existe otro tipo de tenencia de la tierra que se denomina derecho de gestión (hak pengelolaan), esta es la autoridad delegada de un Estado para gobernar y administrar un terreno para ciertas agencias gubernamentales y gobiernos locales. Además de usar la tierra para sus propios fines, estas agencias pueden permitir que otros usen la tierra y proponerles obtener derechos sobre la tierra. Dado que el derecho de gestión no es un derecho sobre la tierra, el derecho de gestión solo puede registrarse, pero no se le concede ningún certificado de propiedad (SAFITRI 2015, 24). 
La Ley número 41/1999 sobre silvicultura establece que la propiedad del bosque consiste en: bosque estatal (hutan negara) y bosque con título (hutan hak). El bosque estatal se encuentra en tierras sin título. Por el contrario, el bosque con título se encuentra en todas las tierras tituladas, incluido el bosque en tierras de propiedad. El Ministerio de Ambiente y Forestal anunciado en 2015 que 120,7 millones de hectáreas de tierra serán mantenidos como bosques. La mayoría de los funcionarios gubernamentales creen que el área forestal debe ser bosque estatal, pero, no hay ninguna disposición en la Ley 41/1999 que confirme esa posición.

\begin{tabular}{|c|c|c|c|c|c|c|c|c|c|c|c|}
\hline \multicolumn{12}{|c|}{ CUADR0 3 LA TENENCIA DE TIERRAS Y BOSQUES EN INDONESIA } \\
\hline & \multicolumn{2}{|c|}{ Bosques titulados } & \multicolumn{3}{|c|}{ Bosques estatales } & & \multicolumn{5}{|c|}{ Tierras } \\
\hline $\begin{array}{c}\text { Tipo de titulo } \\
\text { con ejerce el } \\
\text { derecho }\end{array}$ & $\begin{array}{c}\text { Bosque } \\
\text { consuetudinario }\end{array}$ & $\begin{array}{c}\text { Bosque } \\
\text { de } \\
\text { propiedad } \\
\text { Individuos/ } \\
\\
\text { entidades } \\
\text { legales } \\
\end{array}$ & $\begin{array}{c}\text { Foresteria } \\
\text { comunitaria }\end{array}$ & $\begin{array}{l}\text { Bosque } \\
\text { local }\end{array}$ & $\begin{array}{c}\text { Plantación } \\
\text { forestal } \\
\text { comunitaria }\end{array}$ & \begin{tabular}{|c} 
Bosques \\
de \\
propiedad \\
d de la \\
Villa
\end{tabular} & Propiedad & $\begin{array}{l}\text { Derecho } \\
\text { de } \\
\text { cultivo } \\
\text { comercial }\end{array}$ & $\begin{array}{c}\text { Derecho a } \\
\text { construir una } \\
\text { casa }\end{array}$ & $\begin{array}{c}\text { Derecho } \\
\text { a usar la } \\
\text { tierra }\end{array}$ & $\begin{array}{c}\text { Derecho } \\
\text { a } \\
\text { arrendar } \\
\text { tierra } \\
\text { para } \\
\text { construir }\end{array}$ \\
\hline $\begin{array}{c}\text { Autoridad o } \\
\text { titular que } \\
\text { otorga el } \\
\text { derecho }\end{array}$ & $\begin{array}{l}\text { Ministerio } \\
\text { Ambiente }\end{array}$ & $\begin{array}{l}\text { Ministerio } \\
\text { Ambiente }\end{array}$ & $\begin{array}{l}\text { Ministerio } \\
\text { Ambiente }\end{array}$ & $\begin{array}{l}\text { Ministerio } \\
\text { Ambiente }\end{array}$ & $\begin{array}{l}\text { Ministerio } \\
\text { Ambiente }\end{array}$ & $\begin{array}{l}\text { Jefe de } \\
\text { distrito }\end{array}$ & $\begin{array}{l}\text { Ministerio } \\
\text { Ambiente }\end{array}$ & $\begin{array}{l}\text { Tierra } \\
\text { estatal }\end{array}$ & $\begin{array}{c}\text { Tierras estatales; } \\
\text { Tierra manejada } \\
\text { por agencias } \\
\text { gubernamentales } \\
0 \\
\text { corporaciones; } \\
\text { Propiedad } \\
\text { privada }\end{array}$ & \begin{tabular}{|c|} 
Tierras \\
estatales; \\
Tierras \\
privadas; \\
Tierras \\
bajo \\
derecho \\
de \\
manejo \\
\end{tabular} & $\begin{array}{r}\text { Propiedad } \\
\text { privada }\end{array}$ \\
\hline $\begin{array}{l}\text { Forma de } \\
\text { tenencia }\end{array}$ & colectivo & $\begin{array}{l}\text { Individual } \\
\text { /colectivo }\end{array}$ & Comunal & colectivo & Comunal & colectivo & Privada & $\begin{array}{c}\text { Colectivo } \\
\text { entidad } \\
\text { legal }\end{array}$ & Individual & Individual & Uso \\
\hline
\end{tabular}

Todos los derechos a la tierra permiten a sus titulares utilizar la tierra y los recursos naturales que están directamente vinculados a la tierra. Sin embargo, también deben mantener la protección y preservación ambiental (Art. 15 del Ley Agraria Básica).

\subsection{Hallazgos sobre la tenencia en Indonesia}

En relación con la capacidad de la legislación para alcanzar los tres principios de seguridad de la tenencia: la solidez del derecho, la protección del derecho y las garantías del derecho. SAFITRI $(2015,48-50)$ concluye que en todos los regímenes de tenencia, la legislación existente tiene una fuerte Robustez de Derechos lo que significa que la legislación es fuerte para cumplir con los indicadores de legalidad, claridad, paquetes de derechos y duración. En cuanto a la Protección de Derechos su calificación es que estos principios son Muy Débiles. Finalmente califica a las Garantías de los Derechos como Débiles. 
De los regímenes de tenencia analizados por la solidez de los derechos, el bosque con títulos de las personas físicas o jurídicas es el derecho más sólido. La causa de ello es la calidad de la legislación de tierras. Este bosque con títulos existe cuando se han otorgado derechos sobre la tierra. La Ley Agraria Básica y otras leyes de tierras han regulado claramente con respecto a los tipos de títulos de tierras de personas físicas o jurídicas.

La legislación sobre bosques consuetudinarios o el bosque tradicional tiene un respaldo legal muy sólido, desde la Constitución, las leyes y las regulaciones ministeriales. Las leyes definen claramente a los pueblos indígenas como titulares de los derechos del bosque consuetudinario. Aun así también hay leyes que van en otro sentido, la Ley Forestal 41/1999 y la Ley de Villorios 6/2014 requieren que una reglamentación de nivel distrital reconozca la existencia de ciertos pueblos indígenas y sus territorios.

SAFITRI califica el principio de robustez de los derechos de tenencia de bosques de propiedad de las villas como muy débil. La implementación de la Ley 23/2014 sobre Gobiernos Regionales ha afectado la robustez de derechos de las licencias forestales sociales pues retiró la autoridad del gobierno distrital sobre las licencias forestales sociales en favor de los gobiernos provinciales, generando un vacío de la implementación desde 2014. La legislación sobre bosques de propiedad de las aldeas es la más débil para cumplir con todos los principios de seguridad de la tenencia, siendo débil en la robustez de los derechos, Muy Débil en la protección de los derechos y Débil en la garantía de los derechos.

El principio de la protección de los derechos es muy débil en todos los regímenes de tenencia. Esto indica que la legislación de Indonesia no tiene reglas adecuadas sobre el mecanismo de reclamo, resolución de conflictos y compensación. El régimen forestal social está en una situación más débil que el caso de los derechos de los bosques bajo propiedad. La legislación forestal social no tiene normas sobre el mecanismo de reclamo, resolución de conflictos y compensación. La legislación sobre los bosques bajo propiedad a través de la legislación de tierras tiene disposiciones legales sobre la compensación (Ley 2/2012).

La garantía del derecho es mejor que el principio de protección del derecho. Sin embargo, aún es débil garantizar que las personas puedan participar en la toma de decisiones forestales y que el gobierno garantice la sostenibilidad del ecosistema forestal. Aun así, el gobierno ha declarado tener un compromiso de mejorar la prosperidad de las personas, concordante con el hecho de que la mayoría de los regímenes de tenencia están equipados con programas de empoderamiento económico.

SAFITRI (2015) reviso los principios, indicadores y variables sobre la seguridad jurídica de la tenencia forestal, concluyendo que el Bosque bajo 
propiedad es un derecho más fuerte que los derechos de la forestería social en los bosques estatales. Han cumplido los indicadores de la mayoría de la solidez y garantías de los derechos. El bosque de propiedad de personas naturales o jurídicas está en el primer rango con una fuerte solidez pero débiles en cuanto a protección y garantía de los derechos. En el segundo rango están los bosques de la forestería social que tiene buenas disposiciones en las normas sobre algunos aspectos como legalidad, duración y conjunto de derechos, pero son débiles en términos de protección y garantía del derecho.

Las licencias de forestería social, como la forestería comunitaria, los bosques de aldeas y las plantaciones forestales comunitarias tienen una solidez de derechos calificada por SAFITRI (2015) como Moderada. Sin embargo, han tenido mejor situación que los bosques bajo propiedad en el logro de la garantía del derecho, en particular en los temas de participación y empoderamiento económico. Mientras tanto, los bosques de propiedad de las aldeas tienen muchas disposiciones poco claras en cada aspecto de los derechos de tenencia siendo, por lo tanto, el tipo de derecho forestal con una seguridad más débil.

SAFITRI (2015) finalmente concluye que todos los derechos de tenencia forestal son débiles en términos de protección del derecho, pues el manejo de quejas, la resolución de conflictos y la compensación no están regulados adecuadamente. Por lo tanto, recomienda que una futura reforma de la tenencia en Indonesia considere la mejora de la protección del derecho superando las deficiencias antes indicadas e incorporando una solución alternativa de controversias.

\section{Situación de la legislación de tenencia comunitaria en Mozambique}

La legislación que regula la tenencia de la tierra en Mozambique está constituida por la Constitución, Ley de Tierras 19/97 y su reglamento, Ley Forestal y de Fauna Silvestre 10/99, Ley de Conservación. El artículo 109 de la Constitución de Mozambique establece que la tierra es propiedad del Estado y no puede ser vendida. La Política Nacional de Tierras reafirma ese principio, mientras que la Ley de Tierras prohíbe la transferencia del Derecho de Uso y Aprovechamiento de la Tierra (DUAT) (CHIZIANE 2014, 319-320). Esta Ley de Tierra atribuye poderes a las comunidades y autoridades locales para participar en la delimitación de sus áreas de explotación y el reconocimiento por parte del gobierno de estas áreas como una categoría de uso de la tierra con el principal objetivo de proteger el sistema tradicional de uso y aprovechamiento tierra por los productores y ofrecer estabilidad a los campesinos de pequeña y mediana escala (JEMUCE 2016, 117).

El Derecho de Uso y Aprovechamiento de la Tierra (DUAT) es el derecho de poseer la tierra y aprovecharla, no da derecho a vender la tierra o a usarla como garantía de un crédito. El DUAT da acceso también a los otros recursos ahí presentes y a los recursos hídricos presentes en áreas vecinas, defender la posesión 
frente a terceros, transmitirla vía herencia, transmitir las mejoras pudiendo incluso hipotecar las mejoras y bienes inmuebles bajo autorización, estas autorización proviSORIA puede ser usada para obtener crédito (Chiizane 2017, 145). Una de las modalidades de adquisición del derecho de uso y aprovechamiento de la tierra (DUAT) es por ocupación por las comunidades locales, según las normas y prácticas consuetudinarias en lo que no contradiga la Constitución. El DUAT tiene una duración muy larga para los inversionistas y es a perpetuidad para los ciudadanos de Mozambique (CALENGO 2014, 26). El DUAT es otorgado por el Estado proviSORIAmente sujeto al cumplimiento de la inversión sobre la tierra en un plazo de dos años para los extranjeros y de cinco años para los nacionales. La Ley de Tierras (artículo 10.1) considera a las mujeres en igualdad de condiciones para recibir el DUAT (CHIZIANE 2014, 312), una declaración de este tipo es un avance importante y debe ser acompañada de acciones al nivel operativo de difusión e implementación a fin de asegurar su implementación. Más aun considerando que un estudio reciente mostró que los hombres reciben un valor 6 mayor que el que reciben las mujeres por un pedazo de tierra (EXAME 2018, 96).

Las personas físicas y las comunidades locales pueden obtener un DUAT por la ocupación basada en las tradiciones locales, como herencia de sus antepasados; (ii) como resultado de una ocupación de buena fe - ocupación por personas físicas, de buena fe, siempre que estén utilizando la tierra durante al menos diez años. Este tipo de ocupación sólo se aplica a los ciudadanos nacionales; (iii) mediante la autorización de solicitud presentada al Estado como viene establecido en la legislación de tierras. Esta es la única forma de obtención de DUAT que se aplican a personas, físicas y colectivas (JEMUCE 2016, 54-55).

Para Comoane (citado por CHIZIANE 2007, 18) el DUAT tiene una naturaleza híbrida ya 'que el DUAT se presenta como un derecho real cuando se trata de situarlo en el ámbito de las relaciones jurídicas entre particulares. En las relaciones en que el Estado u otros entes públicos, en particular los municipios locales traban con el ciudadano y cuando estos entes actúan en virtud del poder público, el DUAT presenta características de un derecho regulado por el Derecho Público. Los litigios emergentes de estas relaciones deben ser resueltos por el Tribunal Administrativo'. Esta naturaleza hibrida genera dificultades para identificar su contenido y su medio de defensa, cuando el conflicto relativo a un DUAT involucra partes que son particulares entonces el espacio jurisdiccional es un tribunal común, sin embargo cuando una de las partes es un órgano del aparato público entonces el conflicto debe ser resuelto por un tribunal administrativo (CHIZIANE 2007, 19).

La Ley de Tierras y el Reglamento de la Ley de Tierras imponen como requisito fundamental para la asignación del DUAT, previa solicitud de autorización del DUAT, la realización de una consulta comunitaria. Las consultas enfrentan varios problemas para ser exitosas: Verificar si el proceso involucra solo a los líderes locales, en función del mandato del Decreto del Consejo de Ministros 15/2000 o 
si se ha consultado realmente a todos los co-titulares del DUAT de la comunidad local tal como pide la Ley de Tierras y su Anexo Técnico (TANNER 2004, 18); si se ha cumplido con verificar los elementos sustantivos que acreditan el objeto de la consulta; si consta en acta debidamente elaborada y suscrita; si contiene la información sobre el solicitante, área pretendida y finalidad, entidad que dirige la sesión, presentes, posición de los diversos miembros de la comunidad local, compromiso asumido por el solicitante, opinión del Director Distrital de Agricultura y del Administrador del Distrito (CHIZIANE 2007, 21).

La legislación de Mozambique tiene una preocupación importante por los derechos comunitarios, así como por el conocimiento tradicional asociado a las poblaciones locales. ${ }^{(7)}$ SERRA y Cunha $(2008,170)$ señalan que el concepto de comunidades locales que aparece en la Ley de Tierras es un cambio fundamental frente a lo que fue el concepto tradicional de personalidad jurídica prevista en el derecho civil. Sin embargo muchos de los instrumentos legales que la regulan no son del dominio público, algunas veces incluso ni de los funcionarios, especialmente administrativos distritales (Nhantumbo y MacQueen 2003 citado por SERRA s/f, 578; JEMUCE 2016, 125).

Las tierras de dominio público comunitario son terrenos cuyo uso y aprovechamiento solo puede ser más beneficioso mediante el régimen de la posesión colectiva, se prestan para la realización de fines comunes sean económicos o no. Las tierras comunales existen en virtud de la Ley de Tierras (art 14), que establece que ciertas áreas el régimen de acceso y uso debe ser gobernado según las normas y practicas consuetudinarias y en beneficio de los residentes locales. Estas se ubican en áreas rurales y urbanas siempre que no estén en zonas de áreas legalmente reservadas (CALENGO 2014, 67). CHIZIANE $(2007,25-26$ y 2017,142$)$ y SERRA (s/f, 580) identifican los problemas en el respeto a los derechos comunitarios como: ausencia de criterios claros sobre el ejercicio de la representación de los intereses de las comunidades locales; problemas de transparencia en los procedimientos de consulta comunitaria en el marco de la asignación del DUAT; deficiente contribución de la legislación sobre tierras para promover la inversión privada extranjera, y asegurar beneficios para la población y para el erario público nacional; uso insostenible de los recursos naturales para garantizar la calidad de vida para las presentes y futuras generaciones; deficiente conocimiento y aplicación de la legislación sobre tierras por la administración pública y los propios ciudadanos.

(7) Estos derechos consuetudinarios se apoyan en el presencia de conceptos y autoridades tradicionales como el Mambo que es el espíritu religioso y político del antepasado del linaje, donde se inspira todo el poder tradicional y que es asumido materialmente por el Nhakwawa); el Nhakawawa es la persona que recibe los poderes delegados por el Mambo, convirtiéndose en jefe de muchos linajes dentro de un territorio y es la cabeza del sistema jerárquico de linajes; el Mfumo que asume la jefatura de más de un linaje dentro del territorio línea, pero no cubre su totalidad, se subordina al Nhakawawa y cumple sus órdenes y el Mwananfumo; es jefe de un linaje y es elegido por el Mfumo (Jemuce 2016, 52). 
Las tierras tituladas son tierras donde se ha otorgado un DUAT (artículo 12 Ley de Tierras) estos pueden ser terrenos que antes fueron tierras libres o tierras comunitarias pero donde por efecto de la posesión de más de 10 años, en el primero, o por el consentimiento de la comunidad, en el segundo, se ha constituido un DUAT. Estas tierras deben inscribirse en el Catastro Nacional de Tierras o en el Registro Predial, sin embargo no hay obligación legal de registrarse (CALENGO 2014, 72). Si bien formalmente en la distribución de la tierra en Mozambique no existe ninguna forma de propiedad privada de la tierra, en la práctica, a través del DUAT o sin él, cada familia campesina tiene el derecho de utilizar la tierra y transmitir este derecho a través de la herencia o la tradición consuetudinaria oral.

\begin{tabular}{|c|c|c|c|c|c|c|c|c|c|c|c|c|}
\hline \multicolumn{13}{|c|}{ CUADRO 4 DERECHOS DE TENENCIA EN MOZAMBIQUE } \\
\hline \multirow{2}{*}{$\begin{array}{c}\text { Relación } \\
\text { con } \\
\text { el } \\
\text { titular } \\
\text { del } \\
\text { área }\end{array}$} & \multicolumn{9}{|c|}{ TIERRAS } & \multicolumn{3}{|c|}{ BOSQUES } \\
\hline & \multirow{2}{*}{$\begin{array}{c}\text { Estado } \\
\text { Nacional }\end{array}$} & \multirow{2}{*}{$\begin{array}{l}\text { Gobierno } \\
\text { Autárquico } \\
\text { Provincial }\end{array}$} & \multirow{2}{*}{$\begin{array}{r}\text { Gobierno } \\
\text { Autárquico } \\
\text { Distrital }\end{array}$} & \multirow{2}{*}{ Comunal } & \multicolumn{2}{|c|}{ Tierras Comunales } & \multirow{2}{*}{\begin{tabular}{|} 
Tierras \\
tituladas
\end{tabular}} & \multirow{2}{*}{$\begin{array}{l}\text { Tierras } \\
\text { libres }\end{array}$} & $\begin{array}{c}\text { Áreas } \\
\text { Protegidas }\end{array}$ & \multicolumn{3}{|c|}{ Bosques de Producción } \\
\hline $\begin{array}{c}\text { Tipo } \\
\text { de } \\
\text { título }\end{array}$ & & & & & Registradas & $\begin{array}{c}\text { No } \\
\text { registradas }\end{array}$ & & & $\begin{array}{l}\text { Plan de } \\
\text { Manejo }\end{array}$ & $\begin{array}{r}\text { Concesiones } \\
\text { forestales }\end{array}$ & $\begin{array}{l}\text { Licencias } \\
\text { simples }\end{array}$ & Plantaciones \\
\hline $\begin{array}{l}\text { para } \\
\text { ejercer } \\
\text { el } \\
\text { derecho }\end{array}$ & \multicolumn{12}{|c|}{ Tierras del Dominio Publico } \\
\hline $\begin{array}{c}\text { Forma } \\
\text { de } \\
\text { tenencia }\end{array}$ & \multicolumn{4}{|c|}{ Posesión } & \multicolumn{4}{|c|}{ Posesión } & Uso & $\begin{array}{l}\text { Uso } \\
\text { forestal }\end{array}$ & $\begin{array}{l}\text { Uso } \\
\text { forestal }\end{array}$ & Uso \\
\hline \multicolumn{13}{|c|}{ aboración propia } \\
\hline
\end{tabular}

Las tierras libres son terrenos donde nadie ha registrado un DUAT o inscrito la tierra en el registro. De existir un posesionario sobre un área tal, este se encuentra en una condición sumamente vulnerable pues su posesión puede ser extinguida por un DUAT otorgado a un tercero. Esta es una preocupación en el medio académico y político (CALENGO 2014; MONTEIRO citado por VERDADE 2010). Es importante considerar que la mayoría de los derechos sobre tierras no están registrados en el registro ni constan muchas veces en un documento.

El arrendamiento de tierras se permite sin autorización para predios de menos de 2 hectáreas (artículo 16), en aras de facilitar la inversión CHIZIANE (2014, 315-316) propone ampliar este limite a 50 hectáreas. Mientras CALENGO (2014) propone permitir al menos la venta del DUAT ya que no se permite la venta de la tierra. 
En relación con la capacidad de la legislación para alcanzar los tres principios de seguridad de la tenencia: la solidez del derecho, la protección del derecho y las garantías del derecho podemos concluir que la legislación de Mozambique tiene una moderada Robustez de Derechos, esto es el cumplimiento de los indicadores de legalidad, claridad, paquetes de derechos y duración. En cuanto a la Protección de Derechos su calificación es igualmente de Moderada. Finalmente el esquema de Garantías de los Derechos califica como Débil.

De los regímenes de tenencia de la tierra y bosques analizados las tierras otorgadas por los gobiernos nacional y las autarquías provincial y distrital, así como las tierras tituladas califican como moderadas. La causa de que no haya una mayor fortaleza de estos derechos es la ausencia procedimientos detallados de protección y garantía de los derechos de tenencia. Es decir hay derechos robustos formalmente pero carecen de mecanismos detallados de manejo de quejas, resolución de conflictos, compensación, contienen restricciones varias y pocas garantías legales así como también los mecanismos de participación son aun débiles y se carece de garantías de sostenibilidad y de emprendimiento más allá de declaraciones generales y proyectos específicos.

Enfocándonos en la legislación sobre tenencia consuetudinaria esta tiene un respaldo legal formal y declarativo muy sólido, desde la Constitución, las leyes y las regulaciones ministeriales; sin embargo el tema de la sensibilidad de género carece de mecanismos detallados en su implementación. Las leyes definen claramente a las poblaciones tradicionales como titulares de la tenencia de la tierra y como derecho habientes de los bosques. Aun así, también hay leyes que van en otro sentido, y que específicamente en el caso de los bosques colocan restricciones como ser acordes al objetivo del área protegida o reserva o que sean parte del plan de manejo de dicha área. Esto no es que estén mal tales regulaciones, sino que en el marco de este análisis muestran un derecho a la tenencia consuetudinaria que no es ni muy fuerte ni fuerte.

\section{Situación de la legislación de tenencia comunitaria en Uganda}

La Constitución, la Ley Nacional del Ambiente, La Ley Nacional Forestal y de Plantación de Árboles identifican las principales lagunas frente a la tenencia comunitaria y proporcionan estrategias y medidas necesarias para abordarlos (DAVIS 2015, v-viii). La Política Forestal Nacional identifica la indefinición e inseguridad de estos derechos como uno de los factores subyacentes de la deforestación. Los únicos derechos legalmente reconocidos para las comunidades forestales son el derecho de cortar y tomar madera seca o bambú para uso doméstico personal y el derecho de acceder y usar agua de una fuente natural para fines domésticos. La ley no refiere ninguno de los otros derechos del paquete extendido de derechos. Además, el derecho a cortar y tomar madera seca 
o bambú se proporciona de una manera muy ambigua que no ofrece protección significativa.

En su mayor parte, la ley requiere que las comunidades forestales negocien sus derechos bajo los diferentes regímenes de tenencia en cada caso en la gestión forestal en colaboración (respecto de reservas forestales nacionales y las reservas forestales locales) y los regímenes de tenencia de los bosques comunitarios. Así el que la forestería comunitaria no tiene una protección efectiva de los derechos de tenencia, al no tener un marco legal claro y definido de los derechos, más aun los terceros pueden desconocer la existencia de tales derechos y de los titulares de los derechos favoreciendo la vulneración de los mismos. En la mayoría de los casos, las comunidades forestales son pobres, vulnerables, carecen de las habilidades legales y políticas y de las capacidades necesarias para negociar en condiciones que puedan superar esas enormes asimetrías, de las que también nos habla STIGLITZ (2002) en su revisión del caso de la deuda asiática, en una negociación con el Gobierno y otras poderosas partes interesadas. La protección legal efectiva de los derechos de tenencia de las comunidades forestales requiere que los derechos se estipulen de manera explícita e inequívoca en la ley y no que su definición se someta a negociación en cada caso.

\begin{tabular}{|c|c|c|c|c|c|}
\hline \multicolumn{6}{|c|}{$\begin{array}{c}\text { CUADRO } 5 \text { LA TE NENCIA DE TIERRASY BOSQUE S POR PUE BLOS TRADICIONALES } \\
\text { EN UGANDA }\end{array}$} \\
\hline \multirow{2}{*}{$\begin{array}{c}\text { RELACIO } \\
\text { N CON EL } \\
\text { TITULAR } \\
\text { DEL } \\
\text { AREA }\end{array}$} & \multirow{2}{*}{$\begin{array}{c}\text { Propiedad } \\
\text { pueblos } \\
\text { tradicional } \\
\text { es sobre } \\
\text { tierrasy } \\
\text { bosques }\end{array}$} & \multicolumn{2}{|c|}{$\begin{array}{l}\text { Pueblos tradiciona les en posesión o uso } \\
\text { tierras y bosques del Estado }\end{array}$} & \multirow{2}{*}{$\begin{array}{c}\text { Pueblos } \\
\text { tradicional } \\
\text { es en á reas } \\
\text { protegidas }\end{array}$} & \multirow[b]{2}{*}{ U sua rio } \\
\hline & & $\begin{array}{l}\text { Reserv a Fo restal } \\
\text { Nacional }\end{array}$ & $\begin{array}{c}\text { Reserva } \\
\text { Forestal } \\
\text { Local }\end{array}$ & & \\
\hline $\begin{array}{c}\text { TIPO DE } \\
\text { TITULO } \\
\text { EN EL } \\
\text { QUE SE } \\
\text { EJERCE } \\
\text { EL } \\
\text { DERE CH } \\
\text { O }\end{array}$ & \multirow{2}{*}{$\begin{array}{c}\text { Tierras y } \\
\text { bosques } \\
\text { bajo titulo } \\
\text { de } \\
\text { propiedad } \\
\text { comunal } \\
\text { según Ley } \\
\text { Vida } \\
\text { Silvestre } \\
\text { Sección } \\
8(1) \\
\text { Propiedad } \\
\text { comunal }\end{array}$} & \multirow{2}{*}{$\begin{array}{l}\text { A través de Aauerdo } \\
\text { especifico y segím Plan de } \\
\text { Manejo } \\
\text { Posesión }\end{array}$} & \multirow{2}{*}{$\begin{array}{l}\text { A través de } \\
\text { Acuerdo } \\
\text { especifico y } \\
\text { segun Plan } \\
\text { de Manejo } \\
\text { Posesión }\end{array}$} & \multirow{2}{*}{$\begin{array}{c}\text { Pueblos } \\
\text { indigenas } \\
\text { no } \\
\text { contactados } \\
\text { en posesión } \\
\text { de } \\
\text { concesión } \\
\text { forestal }\end{array}$} & $\begin{array}{l}\text { Derecho de } \\
\text { Uso para } \\
\text { cortar } \\
\text { madera seca } \\
\text { o bambú }\end{array}$ \\
\hline $\begin{array}{c}\text { FORMA } \\
\text { DE } \\
\text { TE NENCI } \\
\text { A } \\
\end{array}$ & & & & & Uso \\
\hline & & , & A Da & & \\
\hline
\end{tabular}

La Ley del Agua, sección 7 (1), establece que una persona, sea ocupante o residente en cualquier tierra donde haya una fuente natural de agua, puede usar esa agua para uso doméstico, combatir incendios o regar una chacra de subsistencia. Además, la Ley del Agua estipula que un ocupante o residente puede, con la aprobación de la autoridad responsable del área, usar cualquier agua subterránea 
en la tierra ocupada por este o en una tierra adyacente a esa, aun cuando este derecho está sujeto al poder del Ministro para regular cualquier fuente de agua imponiendo restricciones o condiciones para el ejercicio de este derecho.

La Ley de Vida Silvestre de Uganda autoriza al Ministro responsable a declarar un área como área de conservación de la vida silvestre (Sección 17). Muchas de estas áreas suelen ser bosques. La ley también tipifica como delito el ingreso no autorizado de cualquier persona a un área protegida de vida silvestre o tome cualquier bien de allí (Sección 22). El Ministro está facultado para establecer áreas de vida silvestre en las que los habitantes que poseen derechos de propiedad sobre la tierra pueden llevar a cabo actividades para el manejo y la utilización sostenible de la vida silvestre siempre que estas no afecten negativamente a la vida silvestre (Secciones 18(3) y 18 (8)). La Sección 25 (1) reconoce y reserva los derechos históricos de las personas en áreas de conservación, ${ }^{(8)}$ y así como dispone que la Autoridad de Vida Silvestre establezca pautas para el acceso de las comunidades de áreas de conservación vecinas a los recursos que son cruciales para su supervivencia. DAVIS $(2015,21-29)$ señala que hasta 2015 no se habían elaborado estas pautas.

Las Directrices de Manejo Forestal Comunitario establecen que los derechos, roles, responsabilidades, autoridad y beneficios de las diferentes partes interesadas (gobierno, inversionista o comunidad) se recogen en un Acuerdo de MFC, el mismo que debe ser concordante con el Plan de Manejo Forestal, cuando este existe. ${ }^{(9)}$ Así los derechos de las comunidades forestales caducan con la expiración del Acuerdo.

La Ley de Tierras enumera los derechos básicos de los miembros de una comunidad bajo un esquema común de manejo de tierras; estos incluyen el derecho a hacer un uso razonable de la tierra común, en conjunto con todos los demás miembros del grupo (Sección 26 (1) a); el derecho de recolectar combustible de madera y materiales de construcción y cosechar los recursos de la tierra común de acuerdo con los términos del esquema (Sección 26 (1) b); y el derecho de excluir a terceros, salvo aquellos que no son miembros pero a quienes se les ha permitido ingresar y usar la tierra común (Sección 26 (1) d). La ley también protege otros derechos básicos que puedan ser propuestos por un acuerdo cooperativo de manejo tierras y acordados por la comunidad (Sección 26 (1) i).

(8) Estos derechos se han preservado bajo diferentes leyes previas a la entrada en vigor de la Ley de Vida Silvestre.

(9) El Acuerdo MFC es un acuerdo en el que una comunidad local y una autoridad gubernamental comparten roles, responsabilidades y beneficios con el fin de administrar una reserva forestal local o central o parte de ella por 5 años. En Uganda, este enfoque se aplica principalmente en las Reservas Forestales Centrales (CFR) que son administradas por la Autoridad Forestal Nacional (NFA). Las comunidades obtienen beneficios por sus responsabilidades en la gestión conjunta. Estas responsabilidades incluyen patrullas forestales y monitoreo de actividades ilegales otras. 
La ley no tiene una disposición explícita sobre cómo manejar las disputas sobre los derechos de tenencia bajo el esquema común de administración de tierras. El artículo 25 de la Ley de Tierras establece que entre los contenidos de un plan común de gestión de tierras se incluyen las sanciones que pueden imponerse a quienes violen los términos del plan, incluidos los motivos para excluir a cualquier persona del uso de la tierra común. En caso de que un miembro no esté satisfecho con una decisión de un Acuerdo de Manejo de Tierra Común realizado en relación con la gestión de un plan común de gestión de tierras, incluidas las decisiones sobre derechos de tenencia, la ley permite que las personas agraviadas apelen la decisión ante el Tribunal de Tierras del Distrito, el que puede confirmar, modificar, o revocar la decisión. Se puede establecer un esquema común de manejo de la tierra por un período específico sin embargo acaban cuando caduque el esquema.

\subsection{La posible evolución de la tenencia en Uganda}

Para superar estas debilidades y vacíos DAVIS (2015) propone que debería: a) Asegurarse el registro y documentación de los derechos de tenencia de las comunidades forestales (a fin de que las sucesivas generaciones de comunidades forestales conozcan y reivindiquen sus derechos y ayude a reducir la incidencia de violaciones de los derechos y las disputas que surgen de la falta de pruebas sobre los derechos); b) Proteger las tierras comunales bajo tenencia consuetudinaria para que no sean convertidas en propiedad absoluta (como un medio de asegurar que las futuras generaciones de comunidades forestales tengan tierras y bosques); c) Establecer mecanismos claros, accesibles y asequibles para resolver disputas (así como reconocer la legitimidad de los mecanismos de resolución de conflictos basados en la comunidad y consuetudinarios); d) Proporcionar remedios claros y efectivos en caso de violación de los derechos de tenencia de las comunidades forestales (incluyendo restitución, indemnización y compensación para reparar a las víctimas de la violación de los derechos de tenencia); e) Los bosques comunitarios solo deben ser manejados por las organizaciones de la sociedad civil ubicadas en las comunidades relevantes y sus alrededores tienen derecho a participar en el manejo de dichos bosques; f) Establecer requisitos de reporte de las agencias estatales sobre las medidas adoptadas a nivel local y nacional para promover y proteger los derechos de tenencia de las comunidades forestales: y g) Proteger el derecho de las comunidades forestales a sus créditos de carbono.

\section{Temas comunes sobre tenencia comunitaria en Perú, Indonesia Mozambique y Uganda}

Los Estados han reconocido formalmente y de diferentes maneras los derechos a la tenencia comunal de tierras y bosques. La legislación otorga varios derechos de tenencia forestal para las comunidades locales y los pueblos indígenas. El bosque bajo título de propiedad es un derecho más fuerte que los derechos de la forestería social en los bosques estatales. Sin embargo, favorece la titulación individual de 
la tierra, pese a que es la fuerza que impulsa la conversión de la cubierta forestal afectando la tenencia comunal y publica (SORIA 2016 b, 44). Igualmente en los cuatro países revisados hay una contienda entre la tenencia de la tierra individual y la tenencia comunal y pública de la tierra que se refleja también en los debates políticos entre las fuerzas políticas, los movimientos sociales como los pueblos indígenas y los inversionistas (SORIA 2016 b, 44).

Los procesos internacionales en curso en apoyo de los servicios ecosistémicos, REDD y economía verde han favorecido los esfuerzos por formalizar la tenencia de la tierra y recursos forestales. La Convención Marco de las Naciones Unidas para el Cambio Climático, la Convención de Diversidad Biológica y la Convención de las Naciones Unidas de Lucha contra la Desertificación, el Compromiso de Bonn, los Objetivos de Desarrollo Sostenible y el Acuerdo de París impulsan las metas de restauración de tierras y bosques degradados, fortalecer la resiliencia de los ecosistemas, la gestión integrada de paisajes, la capitalización de los servicios ambientales, la promoción del manejo forestal sostenible y el aprovechamiento sostenible de recursos naturales, financiados muchas veces por el Fondo Verde del Clima (SORIA y Summers 2017, 23; SORIA 2018). Para que este panorama optimista sea realidad es indispensable la formalización de la tenencia de la tierra y recursos forestales y su acompañamiento con una robusta Protección de Derechos y Garantías más sólidas, especialmente frente a los conductores de la deforestación y la degradación.

En un contexto favorable a las propuestas de REDD, esto también ha servido para promover el diálogo entre los pueblos indígenas, el Estado y la cooperación internacional en torno a las políticas públicas necesarias para hacer viable el negocio de REDD, incluida la seguridad jurídica de la tenencia de la tierra. Por lo tanto, organizaciones de pueblos indígenas han acordado con los gobiernos, ONU-REDD, el Banco Mundial y el PNUD, establecer un marco general para la implementación de estos proyectos REDD (SORIA 2016 b, 22).

La gestión de recursos naturales basada en las comunidades necesita una voluntad política nacional y regional específica sobre el apoyo a la gestión de recursos naturales basada en la comunidad que ayude a hacer realidad con recursos humanos y financieros. Para la gestión de paisajes se requiere una gestión integrada orientada a maximizar la producción pero también a la adaptación y mitigación del cambio climático y otras necesidades de la sociedad y la naturaleza. Necesitamos aprender de la aplicación flexible utilizada por los manejadores de bienes comunes favoreciendo la negociación y la compensación (SORIA 2016 b, 19).

El proceso de descentralización no ofrece mucha esperanza para los bosques pues el liderazgo político regional está muy influenciado por las fuerzas económicas y políticas regionales, que son más indulgentes con la deforestación en aras del crecimiento económico. 
Los funcionarios deben superar un esquema limitado solo al control y vigilancia y transitar hacia un desarrollo de políticas públicas institucionales adaptativas de aprendizaje en cogestión, con comunidades locales y otras poblaciones rurales, en tierras públicas y privadas, como parte de paisajes dinámicos y más complejos. El funcionario debe regular y gestionar en la mira de ser un promotor de desarrollo local de actividades sostenibles.

Los retos institucionales a los que nos enfrentamos en el futuro tienen que ver con desarrollar mecanismos administrativos, judiciales y extrajudiciales rápidos frente violaciones de los derechos de tenencia, delitos ambientales y similares; voluntad política proactiva para implementar un sistema integrado multisectorial y multinivel; implementación efectiva de fiscalización y apoyo a la gestión ambiental en las zonas rurales; y la integración de políticas de promoción de para el crecimiento económico sustentable de las comunidades rurales.

Para fortalecer el cumplimiento de la legislación forestal contamos con nuevos instrumentos en apoyo al cumplimiento de la legislación, por ejemplo, los sistemas de monitoreo, reporte y verificación (MRV), que conjuntamente con la investigación y sanción administrativa y penal pueden ser útiles para combatir las fuerzas que lideran la degradación y deforestación. Estos sistemas pueden operar ex-ante y ex-post. Se apoyan en sistemas de información geográfica (GIS o SIG), aprovechan imágenes satelitales y aéreas, establecen plataformas de monitoreo de la degradación y deforestación, generan propuestas de planificación de lo que puede ser una operación, o reportes de lo que ha sido la misma, o alertas de donde están ocurriendo actividades de cambio de uso de la cubierta forestal, sean autorizadas o no. (SORIA 2018)

Para que el monitoreo sea efectivo, la autoridad forestal debe poder comparar la información provista en la planificación con la información en tiempo real de cómo vienen ocurriendo estas operaciones en campo, sean la corta de los árboles, la preparación de las trozas y tablones, su transporte, transformación y comercio. Para ello, los puestos de fiscalización deben contar con conectividad en tiempo real y utilizar un aplicativo que permita subir información detallada de la licencia forestal, el plan de manejo forestal, la guía de transporte, entre otros. Se debe establecer la obligación de reporte diario de la producción en las áreas de corta, los almacenes y aserraderos, provistas por el titular de la licencia, por los puestos fijos de control forestal, así como por los comerciantes intervinientes y los ciudadanos interesados; colocar chips en los camiones a fin de verificar la rutas de sus traslados, los tiempos y lugares de parada entre otros detalles.

Los sistemas de monitoreo pueden ser una herramienta de apoyo a las autoridades forestales nacional, regionales y locales, así como a la sociedad civil. Estos sistemas pueden generar alertas de las actividades de degradación y deforestación. En base a ello las autoridades forestales así como los comités de 
gestión de bosque pueden dar inicio a la verificación en campo y eventualmente al inicio de un procedimiento administrativo sancionador, el mismo que según el caso puede involucrar a la autoridad policial y judicial y contener sanciones penales (SORIA 2018).

De otro lado siendo que el número del personal del Estado es siempre menor que el número de la población, es necesario anidar nuestra fiscalización de la tenencia y del cumplimiento de la legislación no solo en el sector público y sus funcionarios sino también anidar capacidades en los privados y la sociedad civil y así como involucrar a los medios, las ONGs, comunidades locales y el público en general en el combate al crimen forestal, interactuar cooperativamente con otros sectores públicos en el diseño y cumplimiento de las políticas forestales particularmente la prevención, detención y supresión del crimen forestal (CONTRERAS HERMOSILLA 2018, 19-25).

Muchos de los detalles de la legislación se definen en decretos que finalmente pueden restringir o ampliar los derechos establecidos en las leyes, sea legitima o ilegítimamente. En caso de una ilegitimidad, el interesado debe iniciar un procedimiento constitucional o común, lo cual de por si es ya una dificultad para cualquier ciudadano -incluso para organizaciones de la sociedad civil-. Ya hemos visto cómo hay interpretaciones restrictivas de la legislación a través de normas de tercer nivel, como decretos o resoluciones en los cuatro países bajo estudio. Por más que estos impedimentos sean ilegales y vulneren el principio de jerarquía normativa y constitucional, de la titulación comunal, el proceso de cuestionarlo en sede judicial es de por si una barrera demasiado pesada y costosa, peor cuando debes citar en sede judicial al Estado o a un empresario privado.

\section{Conclusiones}

Los cuatro casos revisados analizan la tenencia de la tierra en Estados independientes que vivieron la experiencia de ser colonizados por potencias europeas que introdujeron elementos de sus propios sistemas coloniales, luego de la Independencia experimentaron una transición donde la legislación colonial siguió siendo aplicada, mientras que en las áreas donde la administración pública colonial no se consolidaba se seguían ejerciendo derechos consuetudinarios vinculados a los regímenes pre-coloniales. Estas condiciones generan que luego los Estados independientes encuentren la necesidad de definir una posición frente a la coexistencia de regímenes legales formales y consuetudinarios para la gestión de la tenencia.

FREUDENBERGER $(2013,1)$ propone que valorar que los bosques aún existen porque los arreglos de tenencia consuetudinarios los ayudaron a proteger y estos arreglos pueden permitir que las comunidades locales capturen algunos de 
los beneficios de estos pagos. Asimismo, la tenencia consuetudinaria puede mitigar las presiones, sea reconociendo formal y legalmente, registrando los derechos o implementando un modelo híbrido que combine los sistemas consuetudinarios y los reglamentarios. La creciente mercantilización de los recursos naturales mediante pagos por servicios ecosistémicos requiere clarificar derechos de propiedad existentes.

Los sistemas consuetudinarios pueden ayudar a superar los límites institucionales estatales frente al desafío de áreas a menudo remotas e inaccesibles, reducir costos administrativos y operativos, mejorar la capacidad de supervisión, resolver disputas locales, así como atender reclamaciones territoriales y demandas sociales amplias de poblaciones tradicionales, indígenas y otras rurales. Reconocer los derechos consuetudinarios brinda protección a los propietarios que de otro modo corren el riesgo de perder sus derechos en la transición a los sistemas legales, siendo luego tratadas como invasores y con poca o ninguna compensación.

Jurgen VOEGELE, del Banco Mundial, afirmó el pasado 30 de mayo 2018, en el Global Lanscapes Forum, Creating Markets, Crafting Opportunities, que los derechos de tenencia en su conjunto son importantes, no solo el derecho de propiedad, indicó que, por ejemplo, China no tiene tierras privadas, todas las tierras son otorgadas en cesión, mientras que en Australia el 99\% de la tierra es de la Corona la misma que otorga cesiones de hasta 99 años. De manera que todos los derechos de tenencia, no solo la propiedad, son cruciales para la inversión en la gestión de paisajes.

Algunas de las lagunas en el marco legal son comunes a Perú, Indonesia, Mozambique y Uganda sobre la tenencia consuetudinaria de la tierra son: a) Las normas y prácticas consuetudinarias de la tenencia no están documentadas y, por lo tanto, b) Son desconocidas por el público en general, que son quienes deben respetar y mantener esos derechos sobre la tierra; c) La ley permite la conversión de tierras de tenencia consuetudinaria a propiedad absoluta; d) La conversión de tierras bajo otros regímenes de tenencia a la tenencia consuetudinaria es un caso que rara vez se ve en estos cuatro países; e) Se prioriza un control ex - post cuando más bien es necesario prevenir; y para ello f) Es necesario transitar hacia un desarrollo de políticas públicas institucionales adaptativas de aprendizaje en cogestión, con comunidades locales y otras poblaciones rurales, en tierras públicas y privadas, como parte de paisajes dinámicos y más complejos.

Otra de las grandes ausencias son mecanismos de fácil acceso y bajo costo para hacer cumplir los derechos de tenencia de la tierra y los bosques comunitarios, ni proporciona remedios adecuados y efectivos en caso de violación de los derechos de tenencia. Peor aun cuando miramos a la importancia de las autoridades tradicionales (el Pinkatzari de los Ashanninkas o el Cornesha de los Yaneshas) en la implementación de estos sistemas legales consuetudinarios encontramos que 
hay un desconocimiento generalizado de estos aspectos que solo llegan a ser considerados cuando hay un proceso administrativo o jurisdiccional de por medio y se pide un informe antropológico. Esto es más grave cuando vemos que las autoridades estatales negocian y coordinan con los líderes de las federaciones y las directivas comunales, pero solo tienen capacidad de reconocer a los miembros oficiales de las directivas formales, pero no tienen consciencia de la existencia de autoridades tradicionales acompañando esos mismos procesos. He aquí una agenda de investigación y desarrollo de las políticas en favor de la tenencia comunal.

\section{Bibliografía}

AGRIMAG MOCAMBIQUE 2018, Especial CASP Acesso a terra, acesso a financimento e beneficios fiscais: os principais problemas do sector privado, \# 8, Maio e Junho.

AIDESEP (2016), PTRT3: Titulación Comunal, Tráfico de parcelas y Deforestación, Lima, Junio. PPT.

AMUMPIIRE, Anna (2017), Uganda: Fast Track Guidelines for Benefit Sharing in Forest Management, mayo, en The Monitor, http://allafrica.com/stories/201705120005. html

BRUCE, John W. (1992), 'Questões De Posse Da Terra Em África: Uma Visão Global', Revista Extra, Junho.

CALENGO, André (2014), 'A Classificaçao Das Terras Em Moçambique', en VERDADE, Maria José y Eduardo CHIZIANE (Coordinación) 2014 Direito Da Terra E Questões Agrárias, Maputo, Escolar Editora. Editores E Livreiros Ltda, P 21-76

VERDADE, Maria José y Eduardo CHIZIANE (Coordinación) (2014) Direito da Terra e Questões Agrárias, Maputo, Escolar Editora. Editores e Livreiros Ltda.

CHAMBISSO, Celso (2017), Terra em Moçambique está nas mãos de burócratas, O Pais.

CHIZIANE Eduardo (2014), 'O estatuto jurídico da terra e a promoção do investimento agrario em Moçambique', en VERDADE, Maria José y Eduardo CHIZIANE (Coordinación) 2014 Direito da Terra e Questões Agrárias, Maputo, Escolar Editora. Editores e Livreiros Ltda, p 205-324

CHIZIANE, Eduardo (2017), 'Aspectos jurídicos do papel da administração pública na gestão da terra em Moçambique,' Revista Direito \& Justiça Social, Vila Velha, v. 1, n. 1, jan./jul. 
CHOMSKY, Noam (2015), Magna Carta Messed Up the World, Here's How to Fix It: The "logic" of capitalist development has left a nightmare of environmental destruction in its wake, The Nation, March 23, https://CHOMSKY.info/20150323/

CONTRERAS HERMOSILLA, Arnoldo (2018), Forest Law Enforcement, manuscript.

CRAIG, Anthony Arnold (2011), Fourth Generation Environmental Law:Integrationist and Multimodal, 35 William \& Mary Environmental Law \& Policy Review 771

DA CUNHA, Manuela Carneiro (1990),'El concepto de derecho consuetudinario y los derechos indígenas en la nueva Constitución del Brasil', en Rodolfo STAVENHAGEN y Diego Iturralde, eds., Entre la ley y la costumbre: El derecho consuetudinario en América Latina, México: Instituto Indigenista Interamericano e Instituto Interamericano de Derechos Humanos.

DAVIS, Crystal; Lauren WILLIAMS; Sarah LUPBERGER and Florence DAVIET (2013), Assessing Forest Governance. The Governance of Forests Initiative Indicator Framework, WRI.

EXAME (2018), Mulheres lesadas nas transações de terra, en EXAME, \# 66, Maio.

FAO (2011), Framework for assessing and monitoring forest governance, Rome, FAO-PROFOR

FAO (2012), Voluntary Guidelines on the Responsible Governance of Tenure of Land, Fisheries and Forests in the Context of National Food Security, Rome.

FREUDENBERGER Mark S. (2013), The Future Of Customary Tenure. Options for Policymakers, USAID Issue Brief.

JEMUCE, Jaime Luís (2016), Gentrificação E Urbanização Extensiva: Caso do Distrito de Boane, província de Maputo -Moçambique, Tesis de Maestria, Porto Alegre, Universidade Federal do Rio Grande do Sul-Faculdade de Arquitetura.

MAGALHAES, Felix (2014), Delimitação de Terras Comunitárias (DTC). Sua contribuição na segurança de posse de Terras e no rendimento agrícola "per capita" das famílias rurais em Nicoadala - Zambézia, Maputo, Universidade Eduardo Mondlane-Faculdade De Agronomia E Engenharia Florestal, Mestrado Em Desenvolvimento Rural, Dissertação.

MAHUMANE, Angelina (2017), Lei de Terras: reformar sem ferir a constituição, O Pais-Domingo. 
MAHUMANE, Tomas (2007), Economia da Terra e Redução da Pobreza, Conference paper 22, Conferencia Desafios para a Investigação Social e Económica em Moçambique.

MERINO, Roger (2017), Law and politics of Indigenous self-determination: the meaning of the right to prior consultation, en Irene Watson (Editor) 2017, Indigenous Peoples as Subjects of International Law; Chapter 6.

MIGHOT-ADOLLA, S.E and J. BRUCE, (1994). "Introduction: Are indigenour African tenure systems insecure?", in: John W. BRUCE and S.E. Migot-Adholla (eds.), Searching for land tenure security in Africa, pp.1-13. Washington D.C.: the World Bank.

DAVIS, Ronald (2015), Securing Tenure Rights for Forest Dependent Communities: A Global Comparative Study of Design and Implementation of Tenure Reform, November, Final Report Prepared for CIFOR.

PITMAN, N., E. RUELAS I., D. Alvira, C. VRIESENDORP, D. K. Moskovits, Á. del Campo, T. Wachter, D. F. Stotz, S. Noningo S., E. Tuesta C. y/and R. C. Smith, eds. (2012). Perú: Cerros de Kampankis. Rapid Biological and Social Inventories Report 24. The Field Museum, Chicago.

SAFITRI, M.A. (2010). Forest tenure in Indonesia: The socio-legal challenges of securing communities' rights. Leiden: Leiden University.

SAFITRI, Myrna A. (2015), Assessing Tenure Security of Land and Forestry Rights of Indigenous Peoples and Other Forest Communities in Indonesian Legal Framework, final report submitted to CIFOR, December.

SANTOS, Boaventura De Souza (2002), Towards common sense: Law, Science and Politics in the Paradigmatic Transition, Nueva York y Londres, Routledge.

SERNANP (2017), Sistema de Áreas Naturales Protegidas del Perú. Lista de ANPs, disponible en Pagina Web SERNANP, bajado el 16 de mayo de 2017.

SERRA, Carlos Manuel (2014), Estado, Pluralismo Jurídico e Recursos Naturais. Avanços e recuos na construção de Direito moçambicano, Lisboa, Escolar Editora.

SERRA, Carlos Manuel y Fernando Cunha (2008), Manual de Direito do Ambiente, 2da edição, Maputo, Ministério de Justiça.

SORIA, Carlos Antonio Martin (2010), 'Amazonia' en James Birx, Editor, Encyclopedia of Current Anthropology, Los Angeles, Sage Publications. 
(2015), Increased Relevance And Influence Of Free Prior Informed Consent, Redd, And Green Economy Principles On Sustainable Commons Management In Peru, prepared for IASC 2015 Conference at the University of Alberta, Edmonton, May 25-29, in Journal of Sustainable Development and Policy (JSDLP), Volume 5 (1) Spring (July) (2015) of the Afe Babalola University in Nigeria.

(2016 a), Producto de Consultoría No. 1 Índice de la Legislación Peruana Vigente sobre Tenencia Colectiva de Tierras Forestales Amazónicas en Perú (1969-2016), Lima, elaborado para CIFOR.

(2016 b), Consultancy Product \# 2, Legal Analysis of Peruvian Communal Land Tenure Legislation and Proposal of Indicators to Monitor Improvement, Lima, prepared for CIFOR.

(2016 c), Lecciones aprendidas: Seguridad jurídica en la tenencia de la tierra en ICAA, Lima, USAID - INTE PUCP.

(2017 a), Consultancy Product \# 3, Recommendations for Monitoring Improvement of Peruvian Communal Land Tenure Legislation, Lima, prepared for CIFOR.

(2017 b), La interdisciplinariedad en el derecho. Mi experiencia desde el derecho ambiental, Pólemos.pe, 25 abril.

(2018), Reforestación, un viejo objetivo de la política pública, en Polemos.pe

y Percy Manuel Summers (2017), Limitaciones para la comprensión de los socioecosistemas y su inserción en las políticas públicas, Revista Kawsaypacha \# 7, Lima, INTE-PUCP.

STAVENHAGEN, Rodolfo (1990), 'Derecho consuetudinario indígena en América Latina', en Rodolfo STAVENHAGEN y Diego ITURRALDE, eds., Entre la ley y la costumbre. El derecho consuetudinario en América Latina, México: Instituto Indigenista Interamericano e Instituto Interamericano de Derechos Humanos.

STIGLITZ, Joseph E. (2002), El malestar en la globalización, España, Santillana Ediciones Generales, S.L.

TANNER, Christopher (2004), As bases sociológicas e Politicas da Lei de Terras de Moçambique: Um Guión para Magistrados y Procuradores, sobre los aspectos comunitarios, FAO, CFJJ.

VERDADE (2017), Moçambique exemplo na delimitação de terras, Maputo. 